\title{
Analysis of River Channel Morphology and Riparian Land Use Changes Using Aerial Photographs and GIS
}

\author{
항공사진과 GIS를 이용한 하천형태 및 하천부지 변화추세 분석
}

\author{
Park, Geun Ae* - Lee, Mi Seon* - Kim, Hyeon Jun** - Kim, Seong Joon*** \\ 박 근 애 - 이 미 선 - 김 현 준 - 김 성 준
}

\begin{abstract}
This study is to trace the change of stream shape using the past series of aerial photographs, and to compare the land use changes of riparian area along the stream. For the Gyeongan national stream, aerial photographs of 1966, 1981 and 2000 were selected and ortho-photographs were made with interior orientation and exterior orientation, respectively. Apparent changes of the stream were found that the consolidated reaches of stream by levee construction became straight together with widening of their stream widths. Especially the stream width of inlet part of Paldang lake widened almost twice because of the rise of water level by dam construction in 1974. The land use of riparian areas of three selected years were classified into six categories (water, forest, agricultural land, urban area, road, sandbar) by digitizing method. The forest and agricultural lands decreased and urban area increased as the stream maintenance had been performed.
\end{abstract}

Keywords : Stream shape, Aerial photograph, Land use, Riparian area

* Graduate School, Dept. of Rural Engineering, Konkuk University, Seoul, Korea

** Water Resources Research Dept., Korea Institute of Construction Tech.

*** Dept. of Civil and Environmental System Engineering, Konkuk University, Seoul, Korea

Corresponding Author. Tel.: +82-2-450-3749

Fax: +82-2-444-0186

E-mail address: kimsi@konkuk.ac.kr

\section{Introduction}

During the past couple of decades, the national and local streams have been consolidated for the purpose of protecting the agricultural land, the life and property of inhabitants of riparian area. As results, the flood risk have decreased and the population increased in the riparian areas by levee effect. On the other hand, as the environmental value and the preservation of ecosystem of the stream and riparian areas have grown up, the restoration of flood plain and the stream 
shape came to the front recently. To estimate the possibility of restoration satisfying hydraulically and environmentally, it is necessary to know and understand how the stream shape and land use of riparian areas have been changed. The historical data showing the original situation and temporal and spatial changes will help the contents and the spatial scale of rehabilitation.

Recently, by the rapid development of GIS (Geographic Information System) and RS (Remote Sensing) technologies, it is possible to handle a series of geographical data and make thematic maps that meets a purpose to identify spatial change.

Among the RS data, aerial photograph can be the best data to identify the stream shape and land use of a time because of its high spatial resolution to extract a required information and obtaining the past data of couple of decades ago. There have been many studies to identify temporal changes using aerial photograph. Chun et al. (1995) investigated spatial-temporal channel bed fluctuation and its distribution of deposits using aerial photographs. Jung et al. (2004) analyzed long-term shoreline change using affine transformation method using aerial images.

The purpose of this paper is to present a method to produce geographical information of stream shape and land use using aerial photographs. Also, quantitative comparison of the change of stream shape and land use of riparian areas using GIS is presented. For the Gyeongan national stream, three years $(1966,1981,2000)$ aerial photographs are prepared and analysed.

\section{Study Area and Aerial Photographs Used}

The study area is shown in Fig. 1. Gyeongancheon watershed is located in Yongin-gun and Gwangju-gun and consists of five standard watersheds (Water resources Unit Code by Korea Water Resources Corporation : 101601, 101602, 101603, 101604, 101605) as a part of Han river basin. Because the national and local stream of Gyeongan-cheon watershed have been consolidated and the land use of riparian areas have been changed together during the past couple of decades, it was adopted in this study.

Total 45 aerial photographs were collected from NGII (National Geographic Information Institute) and KICT (Korea Institute of Construction Technology). Table 1 shows the information of selected aerial photographs of three selected years (1966, 1981, 2000). Because aerial photograph of 1966 did not have data for filming camera, information of another year (1983) with the same focal length was used for data processing.

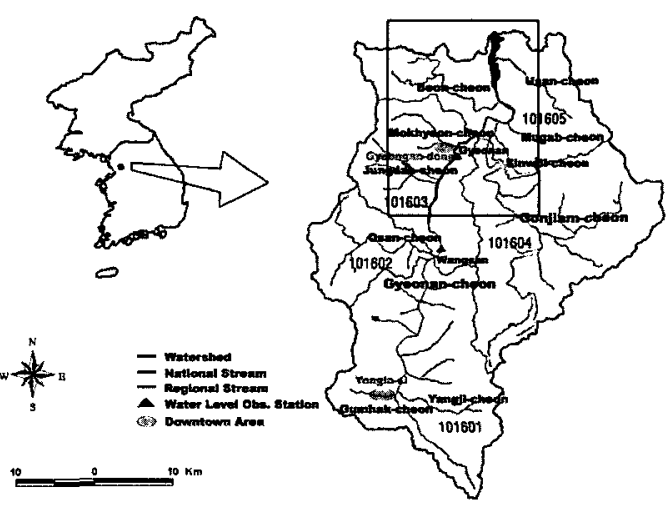

Fig. 1 The study area 
Park, Geun Ae $\cdot$ Lee, Mi Seon - Kim, Hyeon Jun · Kim, Seong Joon

Table 1 Information on aerial photograph

\begin{tabular}{cccccc}
\hline Date & Scale & No. of sheet & $\begin{array}{c}\text { Focal length } \\
(\mathrm{mm})\end{array}$ & $\begin{array}{c}\text { Orbital altitude } \\
(\mathrm{m})\end{array}$ & Type of camera \\
\hline April 1966 & $1 / 37,500$ & 11 & 152.48 & $5,737^{*}$ & RC5/RC8* \\
April 1981 & $1 / 25,000$ & 20 & 152.87 & 3,810 & Wild UAG II 308 \\
April 2000 & $1 / 37,500$ & 14 & 152.54 & 5,715 & RMK A 15/23 \\
\hline
\end{tabular}

* used information of another year (1983) with the same focal length

\section{Creation of Ortho Photographs}

Ortho rectification was accomplished by interior orientation for geometric correction and exterior orientation for elevation fitting.

\section{Interior Orientation}

This is the process of defining the internal geometry of the camera. Fiducial marks are measured on the image and subsequently compared to the calibrated positions of the camera to derive a solution. Once the fiducial marks have been measured, a 2D affine transformation is used to determine the origin of the photo coor-

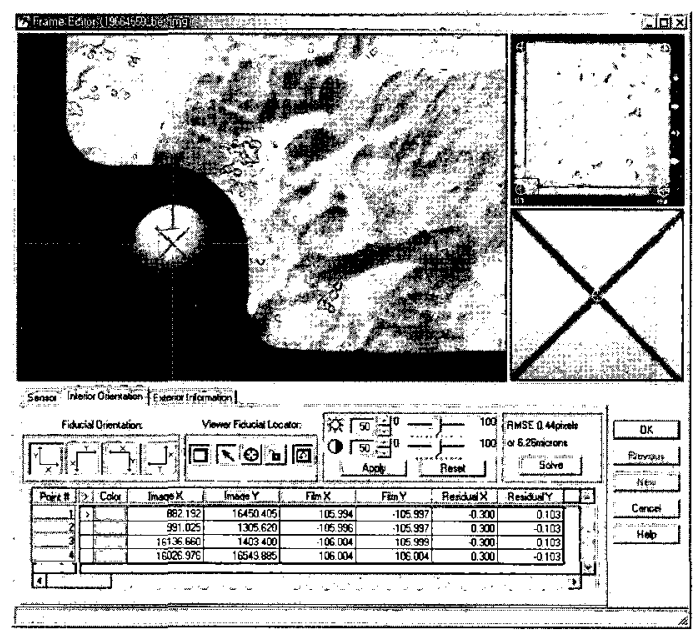

Fig. 2 The example of interior orientation dinate system. The origin of the photo space coordinate system defines the location on the image where the optical axis intersects with the image plane. Once the photo coordinate system has been defined, each subsequent image measurement is referenced to it. Fig. 2 shows the example of interior orientation.

\section{Exterior Orientation}

Exterior orientation describes the location and orientation of an image in the object coordinate system. A total of six transformation parameters per image are typically chosen for such an orientation, namely projection center coordinates (Xo, Yo, and $\mathrm{ZO}_{0}$ ) and three rotations $(\omega, \phi, \kappa)$. The definition of the sequence of rotations has to be

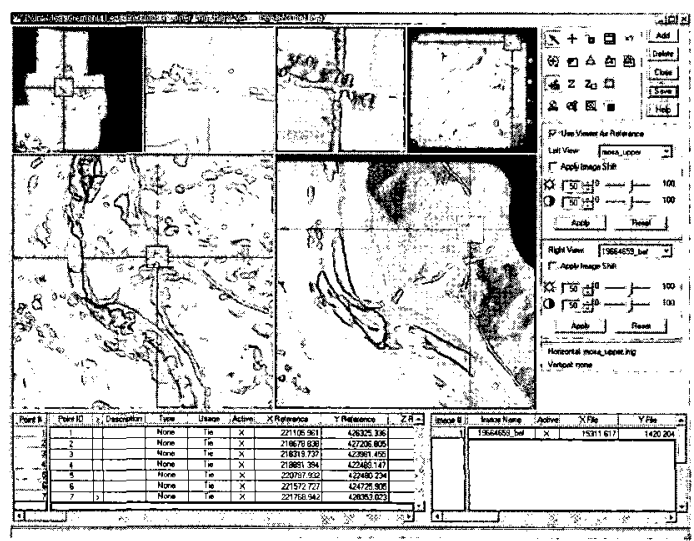

Fig. 3 The example of exterior orientation 
preserved. Exterior orientation is accomplished based on digital elevation model (DEM) to consider spatial relief. Fig. 3 shows the example of exterior orientation.

\section{Digital Elevation Model (DEM)}

Digital elevation model (DEM) for ortho rectification is necessary as a digital file consisting of terrain elevations for ground positions at regularly spaced horizontal intervals (USGS, 1997a and 1997b). DEM was used to analyse topography, modeling and generating data. $5 \mathrm{~m}$ spatial resolution of DEM was created from the topographical layers $(7111,7114,7217,7311)$ of 1:5,000 NGIS (National Geographic Information System) digital map.

\section{Creation of ortho photograph}

Both interior and exterior orientation were executed for each aerial photograph and 45 ortho photos were created using Frame Camera Model of ERDAS (1999) IMAGINE OrthoBASE 8.5. Finally, one ortho photo of each year was created by mosaicking 45 ortho photos for spatial analysis of stream shape and riparian land use.

The average RMSE (root mean square error) of ortho rectification was $1.05,0.54$, and 0.72 pixels on scanning resolution for 1966, 1981, and 2000 ortho photos, respectively.

\section{Extraction of Stream Shape and Ripa- rian Land Use}

It was necessary to mask the mosaicked ortho photo along the stream because the full image was heavy to handle. Fig. 4 shows ortho photograph of each year masked by using map boundary of RIMGIS (river information management GIS).

\section{Stream Shape}

By digitizing, the stream boundary of each year was extracted from the ortho photo of Fig. 4. Fig.

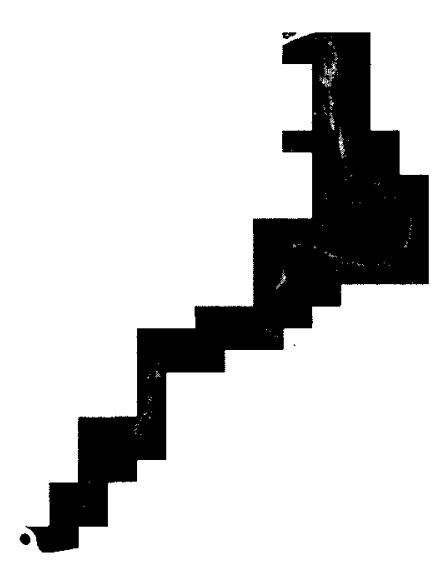

(a)

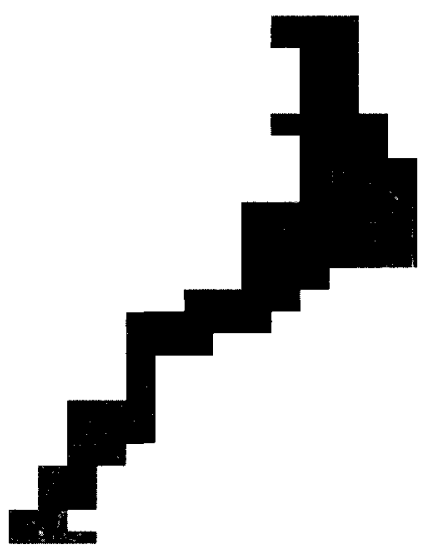

(b)

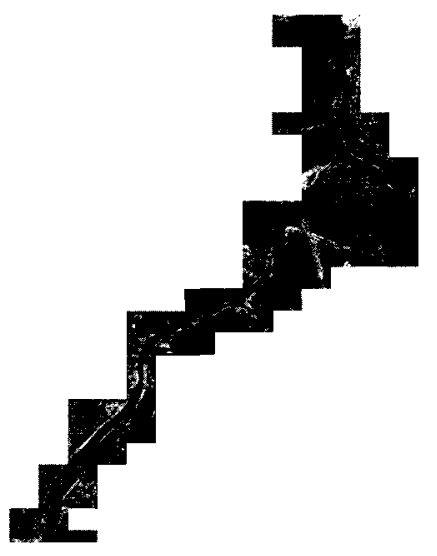

(c)

Fig. 4 Masked ortho photo mosaic of each. year. (a) 1966, (b) 1981 , (c) 2000 


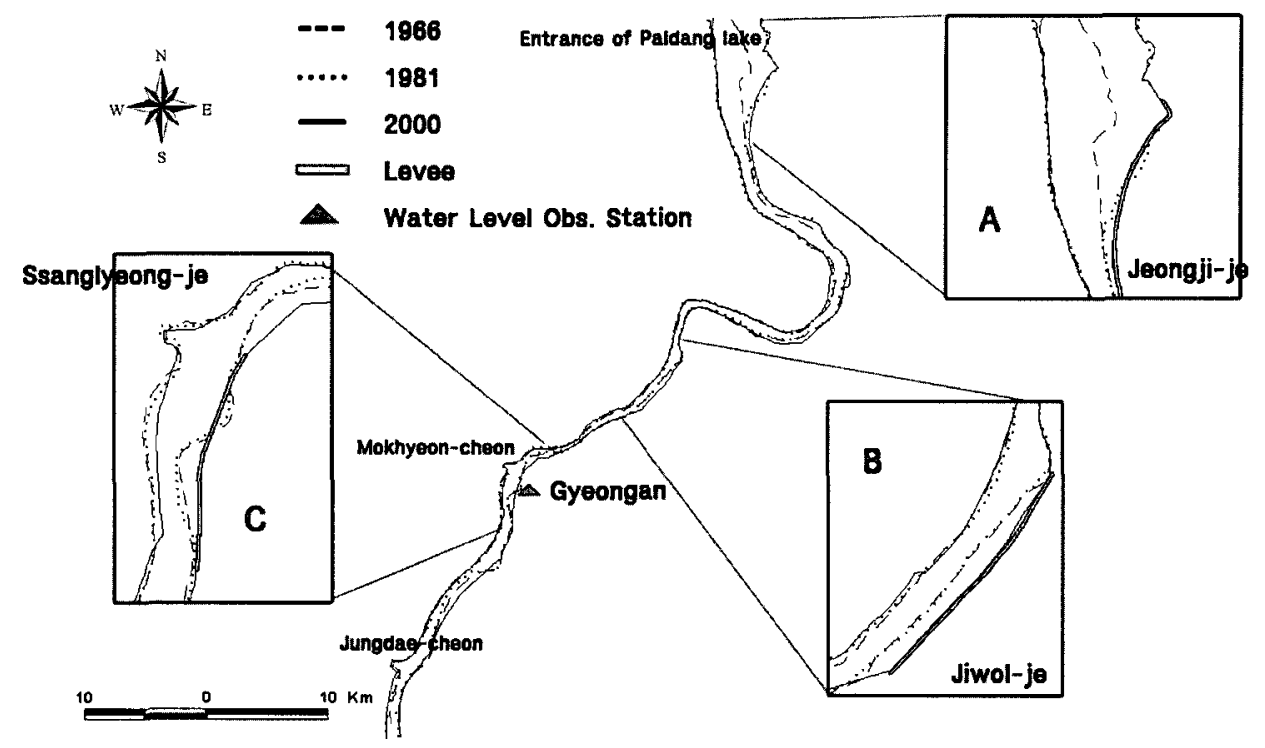

Fig. 5 Extracted stream shape.

5 shows the result of each year and the boundaries are overlaid to compare the change. $\mathrm{Re}^{-}$ markable changes of stream shape were detected at three places by the relocation of stream bank (A: Jeongji-je, B: Jiwol-je, C: Ssanglyeong-je).

Preliminary planning of stream maintenance for Gyeongan watershed was established in 1987. Jeongji-je was constructed in December 1991, and Jiwol-je and Ssanglyeong-je were constructed in June 1998 and December 1989, respectively.

At the location $\mathrm{A}$, the average stream width of $340.9 \mathrm{~m}$ in 1966 broadened almost twice in 1981 due to Paldang dam construction in 1974 at the mouth of Gyeongan stream. At B and C, the average stream width broadened about $25.9 \mathrm{~m}$ and $24.4 \mathrm{~m}$ for the oiginal stream width $104.2 \mathrm{~m}$ and $136.8 \mathrm{~m}$ in 1996 by the stream bank construction of Jeongji-je in 1998 and Ssanglyeongje in 1989, respectively. Also, the stream center lines were extracted and compared. The length of stream shortened from $14.58 \mathrm{~km}$ in 1966 to $14.39 \mathrm{~km}$ in 2000 .

Before bank construction, the flooded water overflowed from the stream bend and formed a natural inundation area nearby. The stream maintenance has been conducted in the meandering part to prevent overflowing the bank especially. Straightening the stream shape and broadening the stream width was carried out to prevent flood inundation. After bank construction, the land value of the natural inundation area rises because of land use change as residential use and land consolidation. Stream bank construction causes the increase of urban land use within the riparian area. This is called a "levee effect".

\section{Riparian Land Use}

Land use map of riparian area was produced by digitizing as shown in Fig. 6. Land use was 


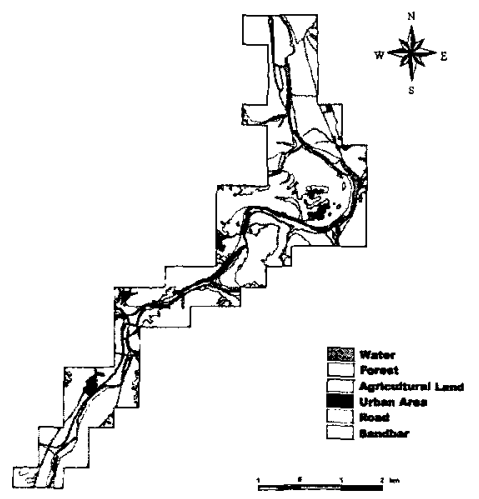

(a)

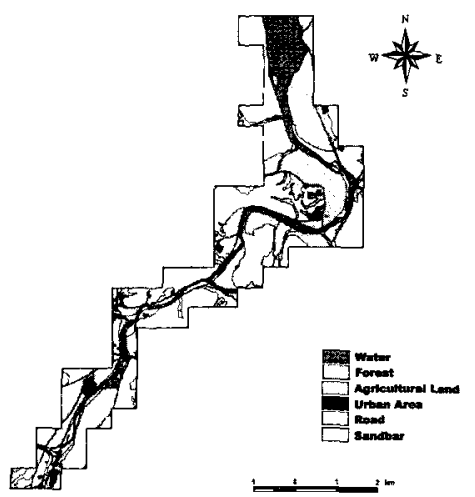

(b)

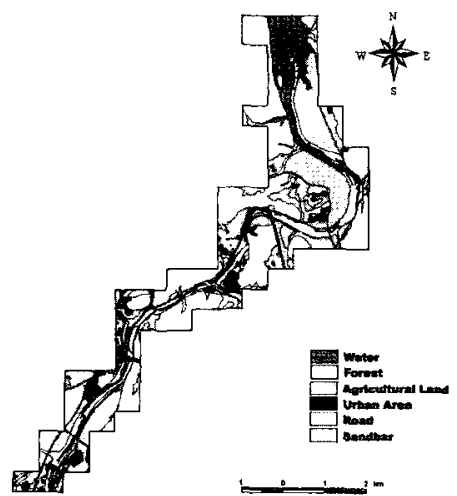

(c)

Fig. 6 Land use of riparian area. (a) 1966, (b) 1981, (c) 2000

Table 2 Land use change for three selected years

\begin{tabular}{lcccrcr}
\hline \multirow{2}{*}{ Categories } & \multicolumn{3}{c}{ Area $(\mathrm{km})$} & \multicolumn{3}{c}{ Ratio of area $(\%)$} \\
\cline { 2 - 7 } & 1966 & 1981 & 2000 & 1966 & 1981 & 2000 \\
\hline Water & 0.75 & 1.73 & 1.58 & 5.0 & 11.5 & 10.5 \\
Forest & 5.51 & 5.32 & 5.11 & 36.7 & 35.4 & 34.0 \\
Agricultural area & 6.92 & 6.76 & 5.85 & 46.1 & 45.0 & 39.0 \\
Urban area & 0.20 & 0.22 & 0.68 & 1.3 & 1.5 & 4.5 \\
Road & 0.08 & 0.19 & 0.35 & 0.6 & 1.3 & 2.3 \\
Sandbar & 1.54 & 0.79 & 1.45 & 10.3 & 5.2 & 9.7 \\
\hline \multicolumn{1}{c}{ Total } & 15.01 & 15.01 & 15.01 & 100.0 & 100.0 & 100.0 \\
\hline
\end{tabular}

classified into six categories such as water, forest, agricultural land, urban area, road and sandbar. Table 2 shows the area of each land use categories in the three selected years.

Sand bar area decreased from $1.54 \mathrm{~km}^{3}$ in 1966 to $0.79 \mathrm{~km}^{2}$ in 1981 . The reason is that the inlet part of Paldang lake at the lower reach of the stream was submerged by the construction of Paldang dam in 1974. After that, the sand bar increased to $1.45 \mathrm{~km}^{2}$ in 2000 . We could identify that the sand bar was mainly recovered at the right upstream reach of the submerged inlet from Fig. 6(c). Forest and agricultural land are de- creased by $2.7 \%$ and $7.1 \%$, and urban area increased by $3.2 \%$ between 1966 and 2000 . This is because of the construction of road and urbanization of riparian area by levee effect.

\section{Summary and Conclusions}

This study analysed the change stream shape and riparian land use using multi-temporal aerial photographs taken in 1966, 1981 and 2000. Ortho photos were produced by image to image for each aerial photograph. After masking ortho photos using the map boundary of RIMGIS, change of 
stream shape was analyzed by comparing the stream centerline and levee boundary of each year. The average width of stream shape widened by the construction of stream bank and the length of stream centerline shortened from $14.58 \mathrm{~km}$ to $14.39 \mathrm{~km}$. Bank construction between year of 1981 and 2000 for the purpose of flood prevention by stream maintenance changed the stream shape to be straight. For the change of riparian area, sandbar was reduced by the construction of Paldang dam in 1974. Forest and agricultural land decreased, however, road and residential area in the riparian areas increased by levee effect.

\section{Acknowledgement}

National Geographic Information Institute (NGII) and Korea Institute of Construction Technology (KICT) provided aerial photographs for this study.

\section{References}

1. Chun, Kun Woo, Kim, Kyoung Nam, Cha, Du Song, 1995, Study on channel-bed fluctuation using aerial photographs (II) - Analysis of spatial-temporal distribution on the deposits -, Journal of Korean Forestry Society, 84(3): 369-376.

2. Jung, Seong Jin, Kim, Kyu Han, Pyun, Chong Kun, 2004, Investigation of long-term shoreline changes using aerial images, Journal of Korean Society of Coastal and Ocean Engineers, 16(1): 10-17.

3. USGS, 1997a. DEM Data User's Guide Version 5, Reston, VA: United States Geological Survey.

4. USGS, 1997b. Standards for Digital Terrain Models, National Mapping Program Technical Instructions. Reston, VA: United States Geological Survey. 